\title{
A METHOD FOR QUANTIFYING BIRD COLONIES IN SAND BARS VIA GPS
}

\author{
RAEDER, F. L. ${ }^{1}$ and BERNHARD, R. ${ }^{2}$ \\ ${ }^{1}$ Divisão do Curso de Ecologia \\ ${ }^{2}$ Coleção de Anfíbios e Répteis, Instituto Nacional de Pesquisas da Amazônia, \\ CEP 69011-970, Manaus, AM, Brazil \\ Correspondence to: Fernando Raeder, INPA - Coleções, Av. André Araujo, 2836, \\ Campus II, C.P. 478, CEP 69083-000, Manaus, AM, Brazil, e-mail: fernandoraeder@ yahoo.com.br \\ Received October 21, 2002 - Accepted January 1, 2003 - Distributed August 31, 2003
}

(With 2 figures)

The management of nesting bird colonies for either commercial exploration or conservation reasons requires that the available resource amount, whether of birds or their eggs, be known (Sutherland, 2000). When the nesting site is constant for every breeding season, various methods exist for this purpose. Just considering ground nesting species, published methods include the use of rope-dragging (Labisky, 1957), mark-and-recapture of individuals (Rotella et al., 1995), radar (Bertram et al., 1999), airplanes (Page et al., 1997), and even helicopters (Gabor et al., 1995). In a situation where a reliable figure, for logistic reasons, is impossible to obtain even using the above methods, a safe estimate should be sought by some other procedure.

That is the case of the Amazonian and Pantanal drainage river beaches, which appear as islands, or sand bars, for a few months every year when the water level is low enough. These sand bars differ in size, shape, and exposure time from year to year, factors that should be taken into consideration when planning a study of bird colonies using these sites for nesting, since all the development phases of the young birds, from laying eggs to learning to fly, should happen before the river level rises again and the beach disappears.

Another aspect to be considered is that not every breeding pair in a colony will lay its eggs at exactly the same time, so at any given moment before the beach is submerged, the colony is composed of nests at different developmental stages, from those just built and empty to those containing eggs, newborn chicks, or a few juve niles. Any method for estimating the total reproductive output in a breeding season (i.e., the number of breeding pairs present at the site, the number of eggs laid, or the number of surviving offspring), must deal with these discrepancies.

In 2001, during a study of a breeding colony of both Phaetusa simplex (Large-billed Tern) and Rynchops niger (Black Skimmer) nesting at a beach of the Solimões River, inside the Mamirauá Sustainable Development Reserve ( $\left.2^{\circ} 44^{\prime} \mathrm{S}, 65^{\circ} 13^{\prime} \mathrm{W}\right)$ in the Brazilian Amazon, we developed a method to estimate the total egg production of the colony for that breeding season. This constitutes the first step towards elaborating a management plan that would allow the collecting of a quota of eggs for consumption by the local villagers. It was unfeasible to count every egg laid, since that beach averages 4 kilometers in length at the end of the low water period, and egg-laying continues for over six weeks, with old and new nests overlapping throughout the entire area.

Since the local belief is that once an egg or hatchling is touched by human hands the parents will abandon it and let it die, villagers would not allow marking or any other type of contact with the birds and eggs, which led us to develop the following method.

To illustrate it, the data from the P. simplex case will be used. The method requires knowing the average incubation period for the species being 
quantified. As used here, this means the time required by each egg to hatch, and not the entire clutch's incubation period as defined by Kendeigh (1963). The average incubation period for a $P$. simplex egg is 24 days (the observed extremes of 23-25 days were probably due to imprecision in estimating the incubation period, since the 40 nests followed to obtain that figure were only checked once daily).

As soon as the water level drops enough to let the beach appear, the first strip of sand should be marked, with both a GPS receiver and a tall stick or pole. As the beach grows, a master-line should be formed by marking and numbering new points every 50 meters on the lengthwise direction of the growing beach (Fig. 1). Usually the first breeding pairs of terns will settle on the beach and start making their nests as soon as the sand is dry enough, which takes no more than a couple of days. So the first counting of bird/nests/eggs should be carried out before the twenty-fourth day after the beach appears to guarantee that no chicks have hatched. One day before counting, a map of the beach should be made in the following manner: using the GOTO function on the GPS, one walks around the entire beach shoreline, and every time the GPS indicates a $90^{\circ}$ position in relation to the nearest marked point on the master-line, that distance is recorded.

Every marked point will have two recorded distances to the water, in directions $180^{\circ}$ opposite each other. Using those distances, at a convenient scale is drawn a "fish-bone" style map of the beach (Fig. 1). Now, for each of the "ribs" on the map, and starting at that line's marked point, adjacent circles with 30 meter diameters are filled in, all the way to the water line (Fig. 2). Only whole circles are to be considered. If at the end of a line a whole circle, does not fit the rest of that line remains empty, since the sand in that beach area is certainly too moist for immediate use by the breeding birds.

The circles are beach areas that will be used in the estimate. In this particular case, the size of the circles was set at 30 meters because after filling all the lines with their circles, the beach area inside the sum of all the circles equaled $47 \%$ of the total beach area. That figure is derived by subtracting the area of the circles from the area of the rectangle formed by the two adjacent "rib" lines. Also, after performing pilot trials, we determined that a circle of that size was ideal since it contained a large enough number of nests while still allowing us not to miss any of them during counting.

The next step was to number each circle drawn on the map, and then randomly select a number of circles equivalent to one-fifth of the total. Therefore, the area inside one-fifth of the circles is equivalent to approximately $10 \%$ of the total beach area. A quota of $10 \%$ of the area is sufficient to represent the entire beach by this random estimating procedure (W.E. Magnusson, pers.comm.), but whenever this method is applied, the researcher should feel free to modify this quota as required. Table 1 shows different percentages obtained by altering the circle sizes and distances between "ribs". Only those circles selected will actually be drawn on the sand. To locate the real position of the selected circles, one stands at the marked point nearest the circle to be found. Again using the GOTO function on the GPS set to that marked point, one follows that "rib" line until situated at the center of the circle. For example, if the circle being located is the second one starting from the marked point, its center will be at the location where the GPS indicates a distance of 45 meters from the mark, since a full circle $(30 \mathrm{~m})$ plus another half $(15 \mathrm{~m})$ to the center of that specific circle would have been walked.

Were it the fifth circle from the line, the GPS would have to indicate $135 \mathrm{~m}$. Such precision on the GPS reading is only possible because a river beach is always an extremely open area, with no satellite signal obstruction. The error margin obtained with our GPS model (Garmin 12 XL) was merely $3 \mathrm{~m}$, which does not compromise the randomness of the method.

To draw the circle on the sand, in a compassstyle an apparatus is used that can be built using two long sticks (in our case two broomsticks) and a 15 meter long chord or rope. Two people are necessary, one to hold one stick at the center of the circle, and another to rotate with the other stick, always keeping the chord as taut as possible to guarantee the correct size of the circle. Eggs and nest counting is done inside the circle boundaries. 


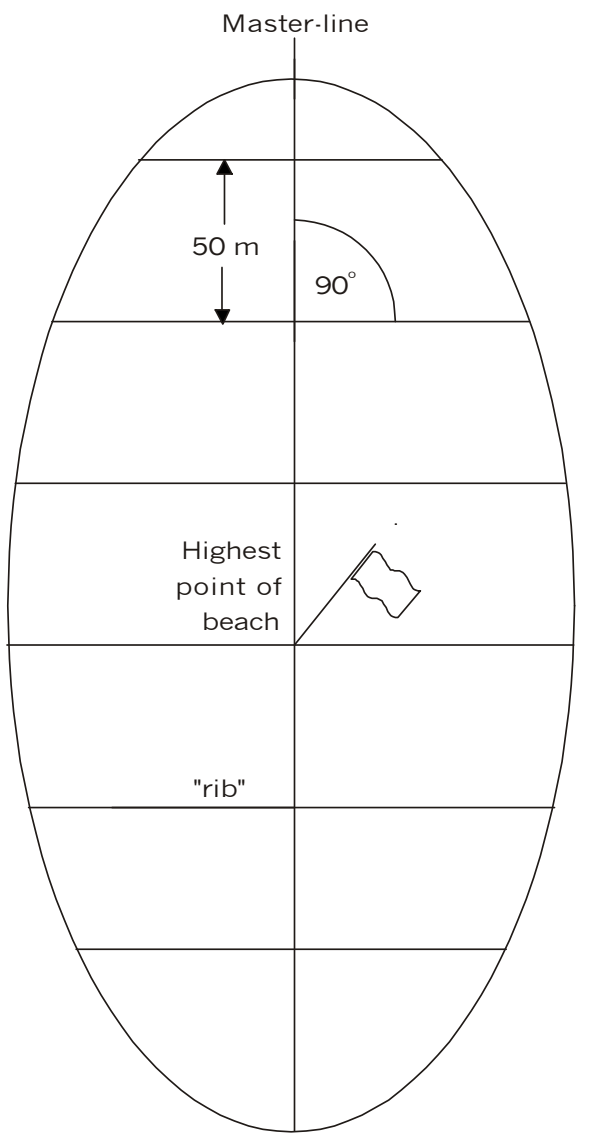

Fig. 1 - First stage of map elaboration.

TABLE 1

Percentage of área covered with differente circle sizes and rib distances.

\begin{tabular}{|c|c|c|c|c|c|c|c|c|c|}
\hline \multicolumn{10}{|c|}{ Diameter of circles (m) } \\
\hline \multirow{9}{*}{$\begin{array}{c}\text { Distances } \\
\text { between } \\
\text { ribs }(\mathrm{m})\end{array}$} & & 5 & 10 & 20 & 30 & 40 & 50 & 75 & 100 \\
\hline & 5 & 79 & & & & & & & \\
\hline & 10 & 39 & 79 & & & & & & \\
\hline & 20 & 20 & 39 & 79 & & & & & \\
\hline & 30 & 13 & 26 & 52 & 73 & & & & \\
\hline & 40 & 10 & 20 & 39 & 59 & 79 & & & \\
\hline & 50 & 8 & 16 & 31 & 47 & 63 & 79 & & \\
\hline & 100 & 4 & 8 & 16 & 24 & 31 & 39 & 59 & \\
\hline & 250 & 2 & 3 & 6 & 9 & 13 & 16 & 24 & 31 \\
\hline
\end{tabular}




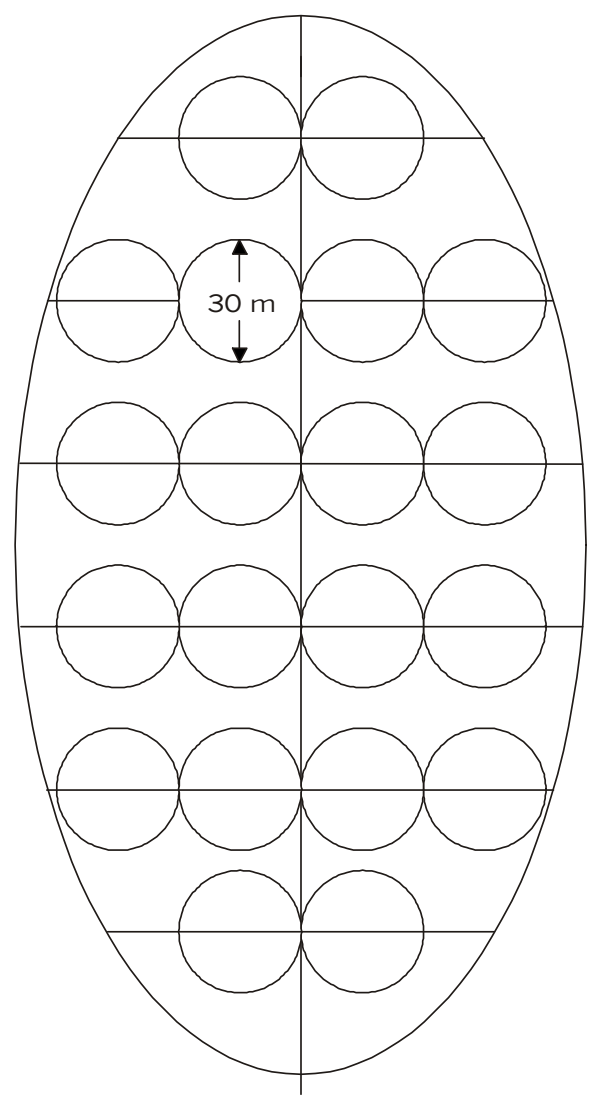

Fig. 2 - Final stage of beach map.

The sand beside each nest counted should be marked to avoid recounting. After all the selected circles are counted, the data is summed and then extrapolated to represent the entire beach. After 24 days (the incubation period for $P$. simplex), a recount must be made to ensure that the new nests built and eggs laid are registered.

By recounting every 24 days, no eggs will be counted twice (except for those few with delayed hatching) and every egg with natural development (that is not predated or lost for some other reason) will have a chance of being counted only once. The recounts must continue while the reproductive season lasts, or until the river level rises and the beach disappears.

At the same site, Fachín-Terán (2001) had been estimating the egg production since 1998. The method consisted of employing a great number of villagers to count daily all new eggs laid, placing a stick besides each nest in the beach for control.

Even though obtained with a different method, our result of approximately 26,000 eggs for 2001 agrees closely with his results for the previous years of 1998, 1999, and $2000(3,000,10,000$, and 20,000 eggs respectively) showing a tendency to increased nesting at the site. This method has the advantage of being inexpensive compared with the other methods, the only really costly equipment being the GPS receiver.

Two people are sufficient to carry out the procedure, and this only during the counting days, with all the time between recounts remaining free. The method also avoids polluting the beach with ribbons, banners, and sticks at each nest. 
Acknowledgments - The authors thank M. López, F. Rego, C. Banks-Leite, and F. "Canela" Nascimento for help in the field; R.C. Vogt for providing the opportunity to develop this method; M. Cohn-Haft for supplying literature and many suggestions on the text. C. Keller, C. Araujo-Lima, and W.E. Magnusson for making valuable comments on the manuscript drafts; and A. Batistella and J. Vale for assistance with the figures. This study was supported by the National Research and Development Council of Brazil (CNPq) and the European Union through the Mamirauá Sustainable Development Institute.

\section{REFERENCES}

BERTRAM, D. F., COWEN, L. \& BURGER, A. E., 1999, Use of radar for monitoring colonial burrow-nesting seabirds. J. Field Ornithol., 70(2): 145-157.

FACHÍN-TERÁN, A., 2001, Preservação de quelônios aquáticos com participação comunitária na RDS Mamirauá. Relatório técnico. Tefé, AM, 51p. (Unpublished.)
GABOR, T. S., GADAWSKI, T. R., ROSS, R. K., REMPEL, R. S. \& KROEKER, D. W., 1995, Visibility bias of waterfowl brood surveys using helicopters in the great clay belt of Northern Ontario. J. Field Ornithol., 66(1): 81-87.

KENDEIGH, S. C., 1963, New ways of measuring the incubation period of birds. Auk., 80: 453-461.

LABISKY, R. F., 1957, Relation of hay harvesting to duck nesting under a refuge-permittee system. J. Wildl. Manage, 21: 194-200.

PAGE, G. W., PALACIOS, E., ALFARO, L., GONZALES., STENZEL, L. E. \& JUNGERS, M., 1997, Numbers of wintering shorebirds in coastal wetlands of Baja California, Mexico. J. Field Ornithol., 68(4): 562-574.

ROTELLA, J. J., DEVRIES, J. H. \& HOWERTER, D. W., 1995, Evaluation of methods for estimating density of breeding female mallards. J. Field Ornithol., 66(3): 391-399.

SUTHERLAND, W. J., 2000, The conservation handbook: research, management and policy. Blackwell Science, Cambridge, 278p. 